\title{
Diabetes Mellitus and Recurrent Tako-Tsubo Syndrome
}

\author{
Walid Hassan*, Mariam Hassan, Atef Ibrahim, Rehab Mohammed, Malik K Malik and Hussain Nassar \\ Department of Cardiovascular Disease, International Medical center, Saudi Arabia
}

Submission: February 09, 2019; Published: March 22, 2019

*Corresponding author: Walid Hassan, MD, MACP, FAHA, FACC, FCCP, FSCAI, Professor of Medicine, Department of Cardiovascular Disease, Director of the Cardiac Center of Excellence, International Medical center, P.O. Box 2172, Jeddah 21451, Saudi Arabia

\begin{abstract}
Tako-tsubo syndrome or cardiomyopathy also referred to as transient apical ballooning syndrome, stress cardiomyopathy or broken heart syndrome is a well-recognized syndrome typically characterized by transient and reversible left ventricular dysfunction that develops in the setting of acute severe emotional or physical stress. Increased catecholamine levels have been proposed to play a central role in the pathogenesis of the disease, although the specific pathophysiology of this condition remains to be fully determined. At present, there have been few reports of Takotsubo cardiomyopathy associated with diabetes mellitus. In this report, we present a 3-years follow-up in a patient with previous multiple recurrences of Takotsubo triggered by diabetic ketoacidosis with resolution and full recovery after strict diabetic control.
\end{abstract}

Keywords: Takotsubo; Recurrence; Diabetes; Ketoacidosis; Cardiomyopathy; Severe emotional; Physical stress; Medical illness; Acute exacerbations; Asthma; Sepsis; Gastrointestinal bleeding

Abbreviations: TC: Cardiomyopathy; TTS: Tako-Tsubo Syndrome; LV: Left Ventricular; ACS: Acute Coronary Syndrome; HF: Heart Failure; DKA: Diabetic Ketoacidosis; ECG: Electrocardiographi; ACEI: Angiotensin Converting Enzyme Inhibitor

\section{Introduction}

Tako-tsubo syndrome (TTS) or Cardiomyopathy (TC) is an increasingly recognized entity characterized by transient (reversible) apical and mid left ventricular (LV) dysfunction in the absence of significant coronary artery disease that is potentially triggered by severe emotional, physical stress, medical illness (acute exacerbations of multiple medical conditions such as asthma, sepsis, gastrointestinal bleeding or 3 hypoglycemia) procedures or surgeries [1-5]. Increased catecholamine levels have been proposed to play a central role in the pathogenesis of this condition [6].

The Takotsubo phenomenon was first described in 1991 by Dote et al. [1], who named the syndrome "Takotsubo like cardiomyopathy" because the appearance resembles a pot historically used in Japan to catch octopi. Other names of this syndrome are Stress-induced Cardiomyopathy, apical ballooning syndrome, broken heart syndrome, ampulla cardiomyopathy [15].

Typically, it recovers to normal LV function in 1-4 weeks. It may account for up to $2 \%$ of suspected acute coronary syndrome (ACS), TTS or TC is much more common in women than men, particularly post-menopausal women [1-3,7]. In a review of six prospective and four retrospective studies women accounted for 80 to 100 percent of cases, with a mean age of 61 to 76 years [7].

Tako-tsubo cardiomyopathy is a diagnosis of exclusion [8]. Researchers at the Mayo Clinic proposed diagnostic criteria in 2004, which include;

i. Transient hypokinesis, akinesis, or dyskinesis in the left ventricular mid segments with or without apical involvement; regional wall motion abnormalities that extend beyond a single epicardial vascular distribution and frequently, but not always, a stressful trigger;

ii. The absence of obstructive coronary disease or angiographic evidence of acute plaque rupture;

iii. New ECG abnormalities (ST-segment elevation and/or T-wave inversion) or modest elevation in cardiac troponin; and

iv. The absence of pheochromocytoma and myocarditis [2].

Numerous etiologies have been described, including catecholamine release during stress [2-5,9,10], and microvascular spasm or ischemia [11,12]. 


\section{Current Research in Diabetes \& Obesity Journal}

Acute complications of TC include arrhythmias, pulmonary edema, cardiogenic shock, transient LV outflow tract obstruction, mitral valve dysfunction, acute thrombus formation, stroke and Death [13].

There are no established treatment algorithms for TC at present, but as most patients present with an ACS or heart failure (HF), they are treated according to ACS/HF guidelines. Tako-tsubo cardiomyopathy is generally a benign condition; inhospital mortality is $0-8 \%$ [13-18].

Recurrent TC disease is rare and only few cases have been previously reported $[4,5,16,17]$. Diabetes has been reported to be protective against TC and a few reported TC in diabetic patient indicating low prevalence (10-20\%) [19-21], in contrast to the high prevalence of diabetes in ACS (52\%) in our previous study [22].

We present in this report a 3-year follow-up of a rare case of recurrent apical ballooning syndrome in a woman with several hospitalizations for chest pain, dyspnea, and electrocardiographic (ECG) changes triggered by diabetic ketoacidosis (DKA) and remarkable resolution and full recovery after strict glycemic control.

\section{The Case}

A 56-year-old female with poorly controlled type 2 diabetes due to medication noncompliance who had 4 hospital admissions over 3 years (2013-2016) for chest pain, dyspnea, acute ST-T elevation, cardiac biomarkers elevation, left ventricular apical severe hypokinesis and ballooning diagnosed by echocardiography. She always received acute coronary syndrome (ACS) management at presentation and had urgent coronary angiogram during the initial three presentations and all revealed normal coronary arteries. The common associated factor in all admissions was the presence of DKA at all presentations. After DKA treatment, she was kept on anti-failure medications in the form of angiotensin converting enzyme inhibitor (ACEI), beta blocker ( $\beta$-blocker), diuretic and aspirin. She recovered fully in few weeks' time after last event $(1 / 2016)$ with normalization of LV function and wall motion in follow up echocardiography (6 months the yearly) and she stopped her cardiac medications except ACEI and beta blocker. Currently, she is stable with much better compliance with diabetic treatment, glycemic control, HbA1c with no further DKA presentation and last echocardiography 36 months after the last TC event showed completely normal LV systolic function.

\section{Discussion}

Tako-tsubo syndrome or cardiomyopathy is a recently recognized entity. Many theories have been presented for the possible pathophysiology of TC. Studies have proposed the mechanism as an association with excessive sympathetic stimulation, microvascular dysfunction, spasm and metabolic abnormalities [1-7,18,23].
Emotional and physical stresses often precipitate the clinical presentation. This suggests a relationship between cortical brain activity (a central catecholamine surge) and myocardial stunning $[1,2,24,25]$.

Studies have found that patients with TC have statistically significant higher levels of serum catecholamines (norepinephrine, epinephrine, and dopamine) than patients with myocardial infarctions [25-27]. Increase beta-2-adrenoceptor activity in the setting of a high catecholaminergic state has been proposed as possible reproducible model for this entity, inducing cardiac dysfunction and myocyte injury though calcium leakage due to hyperphosphorylation of the ryanodine receptor 2 [28]. The apical portions of the left ventricle have the highest concentration of sympathetic innervations found in the heart and increased beta- 2 concentration gradient from apex to base could play an important role in the apical myocardial dysfunction and ballooning commonly found in TC cases [21-25]. Combining the results from multiple studies plasma norepinephrine levels were elevated in $74 \%$ of cases [14].

The pathogenesis of TC may be multifactorial, similar to catecholamine induced cardiomyopathy [27], pheochromocytoma and subarachnoid hemorrhage [28,29].

Catecholamine excess has reversible toxic effects on myocardium that have been documented in cases of pheochromocytoma [27-32]. Histological examination of biopsy samples from the affected left ventricle of patients with TC has shown intracellular accumulation of glycogen, many vacuoles, disorganized cytoskeleton and contractile structure, contraction band necrosis and increased extracellular matrix proteins, which is associated with clinical states of catecholamine excess [33-35]. These alterations resolved nearly completely after functional recovery.

Takotsubo cardiomyopathy is associated with minor release of cardiac enzymes so suggests some microscopic damage to the myocytes. The absence of causative coronary artery disease on angiography and the wall motion abnormalities point to an insult that is microscopic in nature.

Recurrent TC disease is rare and only few cases have been previously reported $[4,5,16,17]$. Data on diabetes as a trigger for TC is scarce and previous reports suggest even a protective role of diabetes against TC $[19,20,21,36]$, as compared to the higher prevalence of diabetes in ACS as shown in our previous study [22].

This the only one documentation regarding recurrent TC triggered by DKA [4]. We strongly believe that the abovementioned catecholamine and neuro-hormonal axis is probably the underlying mechanism that is stressed and over stimulated during DKA as in our patient, overwhelming and counteracting the baseline autonomic neuropathy known in diabetic patient. 


\section{Current Research in Diabetes \& Obesity Journal}

There is no controlled data to define the optimal medical regimen to treat TC during DKA, but it has been postulated that it is reasonable to treat the underlying cause, strict glycemic control and with the standard medications for LV systolic dysfunction. These include ACE I, $\beta$-blocker (or combined $\alpha$ - and $\beta$-blocker), and diuretics, which may be necessary for volume overload states [2]. Aspirin and statin are also reasonable treatment $[8,37,38]$.

It was reported that thrombosis occurs in takotsubo cardiomyopathy cases, which might reflect vasoconstriction, platelet activation, or prothrombotic effects of extremely high epinephrine levels that of course will be more exaggerated in diabetic patients [39-43]. In one study, 5\% of patients with TC developed LV thrombus, and all patients with LV thrombus, were started on anticoagulation and one patient developed stroke [43]. It is reasonable to continue anti-coagulation until the thrombus resolve and left ventricular function improves $[5,44]$.

In our case, after compliance with treatment and strict glycemic control, she recovered well her TC and regular followup echocardiography every 6-12 months remained with normal LV systolic function with no wall motion abnormalities. She was maintained only on ACEI, beta blocker and stopped other cardiac medications. She continues to be asymptomatic lead an active life 3 years after the last TC event.

\section{Conclusion}

To the best of our knowledge, we report a unique first case of multiple recurrences of TC triggered by diabetic ketoacidosis. Our patient was diagnosed 4 times with TC based on the widely accepted Mayo guidelines for TC Prevention with good glycemic control, medications compliance, and avoidance of other triggers have been the key to prevent further cardiac events.

Chronic management of TC is primarily empirical, but there is emerging data supporting the role for alpha and beta blockade. In diabetic patients who are stable, it appears advantageous to prevent excessive sympathetic activation by combining alpha and beta blockade during episodes of ketoacidosis, we also advice ACEI long term if tolerated.

We hope our case contribute to the understanding of this interesting rare condition and will further help in the management of patients with similar conditions.

Lastly, a more complete understanding of the pathophysiology of this syndrome in diabetics awaits further research.

\section{References}

1. Dote K, Sato H, Tateishi H, Uchida T, Ishihara M (1991) Myocardial stunning due to simultaneous multivessel coronary spasm: a review of 5 cases. J Cardiol 21(2): 203-214.

2. Bybee KA, Kara T, Prasad A, Lerman A, Barsness GW, et al. (2004) Systematic review: transient LV apical ballooning: a syndrome that mimics ST-segment elevation myocardial infarction. Ann Intern Med 141(11): 858-865.

3. Tsuchihashi K, Ueshima K, Uchida T, Oh-mura N, Kimura K, et al. (2001) Transient LV apical ballooning without coronary artery stenosis: a novel heart syndrome mimicking acute myocardial infarction. Angina Pectoris-Myocardial Infarction Investigations in Japan. J Am Coll Cardiol 38(1): 11-18.

4. Hassan W, Abou Ghazala T, Sharaf Eldin S (2016) Tako-tsubo Syndrome and Diabetes Mellitus; Review of Literature and A Case Report. ARC J Diab and Endocr 2(1): 19-23.

5. Ahmed A, Serafi A, Mahfouz A, Younes H, Hassan W (2017) Recurrent Takotsubo Syndrome with Prolonged QT, Torsade de Pointes and Left ventricular Thrombus; A Case Report and Review of Literature. J Saudi Heart Assoc 29(1): 44-52.

6. Abraham J, Mudd JO, Kapur NK, Klein K, Champion HC, et al (2009) Stress cardiomyopathy after intravenous administration of catecholamines and beta-receptor agonists. J Am Coll Cardiol 53(15): $1320-1325$

7. Sharkey SW, Lesser JR, Zenovich AG, Maron MS, Lindberg J, et al. (2005) Acute and reversible cardiomyopathy provoked by stress in women from the United States. Circ 111(4): 472-479.

8. Wachsman Daniel (2004) Takotsubo Cardiomyopathy: A Little-Known Cardiomyopathy Makes its Debut. Cardiology 102(3): 119-121.

9. Prasad A, Lerman A, Rihal CS (2008) Apical ballooning syndrome (Tako-Tsubo or stress cardiomyopathy): a mimic of acute myocardial infarction. Am Heart J 155(3): 408-417.

10. Hanna M, Finkelhor RS, Shaw WF, Bahler RC (2007) Extent of right and left ventricular focal wall-motion abnormalities in differentiating transient apical ballooning syndrome from apical dysfunction as a result of coronary artery disease. J Am Soc Echocardiogr 20(2): 144150 .

11. Parsad S (2007) Apical ballooning syndrome: an important differential diagnosis of acute myocardial infarction. Circulation 115(5): e56-e59.

12. Meimoun P, Malaquin D, Sayah S, Benali T, Luycx-Bore A, et al. (2008) The coronary flow reserve is transiently impaired in tako-tsubo takotsubo cardiomyopathy: a prospective study using serial Doppler transthoracic echocardiography. J Am Soc Echocardiogr 21(1): 72-77.

13. Sharkey SW, Windenburg DC, Lesser JR, Maron MS, Hauser RG, et al. (2010) Natural history and expansive clinical profile of stress (takotsubo) cardiomyopathy. J Am Coll Cardiol 55(4): 333-341.

14. Gianni M, Dentali F, Grandi AM, Sumner G, Hiralal R, et al. (2006) Apical ballooning syndrome or takotsubo cardiomyopathy: A systematic review. Eur Heart J 27(13): 1523-1529.

15. Dorfman TA, Iskandrian AE, Aqel R (2008) An unusual manifestation of Tako-tsubo cardiomyopathy. Clin Cardiol 31(5): 194-200.

16. Maroules CD, Linz NA, Boswell GE (2009) Recurrent Takotsubo cardiomyopathy. J Cardiovasc Comput Tomogr 3(3): 187-189.

17. Elesber AA, Prasad A, Lennon RJ, Wright RS, Lerman A, et al. (2007) Four-year recurrence rate and prognosis of the apical ballooning syndrome. J Am Coll Cardiol 50(5): 448-452.

18. Bybee KA, Murphy J, Prasad A, Wright RS, Lerman A, et al. (2006) Acute impairment of regional myocardial glucose uptake in the apical ballooning (takotsubo) syndrome. J Nucl Cardiol 13(2): 244-250.

19. Madias JE (2016) Low prevalence of diabetes mellitus in patients with Takotsubo syndrome: A plausible 'protective' effect with pathophysiologic connotations. Eur Heart J Acute Cardiovasc Care 5(2): 164-170. 


\section{Current Research in Diabetes \& Obesity Journal}

20. Auzel O, Mustafic H, Pillière R, El Mahmoud R, Dubourg O, et al. (2016) Incidence, characteristics, risk factors, and outcomes of takotsubo cardiomyopathy with and without ventricular arrhythmia. Am J Cardiol 117(8): 1242-1247.

21. Madias JE (2016) What Is the Prevalence of Diabetes Mellitus in Patients with Principal and Secondary Takotsubo Syndrome? JACC Heart Fail 4(5): 417.

22. Hassan W, Al-Sergani H, Al Buraiki J, Dunn B, Al Turki F, et al. (2007) Immediate and intermediate results of intracoronary stand-alone bolus administration of eptifibatide during coronary intervention (ICE) study. Am Heart J 154(2): 345-351.

23. Wittstein IS, Thiemann DR, Lima JA, Baughman KL, Schulman SP, et al (2005) Neurohumoral features of myocardial stunning due to sudden emotional stress. N Engl J Med 352(6): 359-348.

24. Singh NK (2008) Apical ballooning syndrome: the emerging evidence of a neurocardiogenic basis. Am Heart J 156(3): e33.

25. Buchholz S, Rudan G (2007) Tako-tsubo syndrome on the rise: a review of the current literature. Postgrad Med J 83(978): 261-264.

26. Dorfman TA, Iskandrian AE (2009) Takotsubo cardiomyopathy: Stateof-the-art review. J Nucl Cardiol 16(1): 122-134

27. Ostadal B, Pelouch V, Ostadalova I, Novakova O (1995) Structural and biochemical remodelling in catecholamine-induced cardiomyopathy: comparative and ontogenetic aspects. Mol Cell Biochem 147(1-2): 8388.

28. Neil-Dwyer G, Walter P, Cruickshank JM, Doshi B, O'Gorman P (1978) Effect of propranolol and phentolamine on myocardial necrosis after subarachnoid haemorrhage. Br Med J 2(6143): 990-992.

29. Nanda AS, Feldman A, Liang CS (1995) Acute reversal of pheochromocytoma-induced catecholamine cardiomyopathy. Clin Cardiol 18(7): 421-423.

30. Ellison GM, Torella D, Karakikes I, Purushothaman S, Curcio A, et al. (2007) Acute beta-adrenergic overload produces myocyte damage through calcium leakage from the ryanodine receptor 2 but spares cardiac stem cells. J Biol Chem 282(15): 11397-11409.

31. Mori H, Ishikawa S, Kojima S, Hayashi J, Watanabe Y, et al. (1993) Increased responsiveness of left ventricular apical myocardium to adrenergic stimuli. Cardiovasc Res 27(2): 192-198.

32. Kassim TA, Clarke DD, Mai VQ, Shakir M KM (2008) Catecholamineinduced cardiomyopathy. Endocr Pract 14(9):1137-1149.
33. Lenders JW, Eisenhofer G, Mannelli M, Pacak K (2005) Phaeochromocytoma. Lancet 366(9486): 665-675.

34. Nef HM, Möllmann H, Kostin S, Troidl C, Voss S, et al. (2007) Tako-Tsubo cardiomyopathy: intraindividual structural analysis in the acute phase and after functional recovery. Eur Heart J 28(20): 2456-2464.

35. Abe Y, Kondo M, Matsuoka R, Araki M, Dohyama K, et al. (2003) Assessment of clinical features in transient LV apical ballooning. J Am Coll Cardiol 41(5): 737-742.

36. Murugiah K, Wang Y, Desai NR, Spatz ES, Nuti SV, et al. (2016) Trends in Short- and Long-Term Outcomes for Takotsubo Cardiomyopathy Among Medicare Fee-for-Service Beneficiaries, 2007 to 2012. JCHF 4(3): 197-205.

37. Yoshida T, Hibino T, Kako N, Murai S, Oguri M, et al. (2007) A pathophysiologic study of tako-tsubo cardiomyopathy with F-18 fluorodeoxyglucose positron emission tomography. Eur Heart J 28(21): 2598-2604.

38. Akashi YJ, Goldstein DS, Barbaro G, Ueyama T (2008) Takotsubo Cardiomyopathy. A New Form of Acute Reversible Heart Failure. Circ 118(25): 2754-2762

39. Sasaki N, Kinugawa T, Yamawaki M, Furuse Y, Shimoyama M, et al (2004) Transient left ventricular apical ballooning in a patient with bicuspid aortic valve created a left ventricular thrombus leading to acute renal infarction. Circ J 68(11): 1081-1083.

40. Kurowski V, Kaiser A, von Hof K, Killermann DP, Mayer B, et al. (2007) Apical and midventricular transient LV dysfunction syndrome (takotsubo cardiomyopathy): frequency, mechanisms, and prognosis. Chest 132(3): 809-816.

41. Kurisu S, Inoue I, Kawagoe T, Ishihara M, Shimatani Y, et al. (2011) Incidence and treatment of LV apical thrombosis in Tako-tsubo cardiomyopathy. Int J Cardiol 146(3): e58-60.

42. Tobar R, Rotzak R, Rozenman Y (2009) Apical thrombus associated with Takotsubo cardiomyopathy in a young woman. Echocardiography 26(5): 575-580.

43. Yoshioka T, Hashimoto A, Tsuchihashi K, Nagao K, Kyuma M, et al (2008) Clinical implications of midventricular obstruction and intravenous propranolol use in transient LV apical ballooning (Takotsubo cardiomyopathy). Am Heart J 155(3): 526.e1-7.

44. Palecek T, Kuchynka P, Linhart A (2010) Treatment of Takotsubo cardiomyopathy. Curr Pharm Des 16(26): 2905-2909.

\section{Your next submission with Juniper Publishers will reach you the below assets}

- Quality Editorial service

- Swift Peer Review

- Reprints availability

- E-prints Service

- Manuscript Podcast for convenient understanding

- Global attainment for your research

- Manuscript accessibility in different formats

( Pdf, E-pub, Full Text, Audio)

- Unceasing customer service

Track the below URL for one-step submission https://juniperpublishers.com/online-submission.php 